\title{
IMPACT OF INFORMATION TECHNOLOGY INNOVATIONS ON FINANCIAL TRANSACTION PROCESSING
}

\author{
Mysore Ramaswamy, Southern University, Baton Rouge, LA, mysore@acm.org \\ Richard Calvasina, University of West Florida, Pensacola, FL, rcalvasi@uwf.edu \\ Eugene Calvasina, Southern University, Baton Rouge, LA, ejcalvasina@cox.net \\ Gerald Calvasina, Southern Utah University, Cedar City, UT, calvasina@suu.edu
}

\begin{abstract}
Due to innovations in Information Technology (IT), we now have the tools to track all business processes both in demand and supply chains in real time. This real time economy presupposes movement of information without hindrance across corporate boundaries, time zones, and systems. Our information age is characterized by technology that accumulates large amounts of data and processes it into meaningful comprehensive information for management. The accounting function, however, still continues to provide the financial information. According to a recent study by Forrester Research, accounting professionals across the country process more than one billion invoices each week, and 97 percent of those invoices are still being processed manually. Automating all processes starting from when a purchase order is generated to when payment is ultimately received creates both new efficiencies and reduced costs by providing better visibility of all aspects of financial transaction processing. This paper first compares the financial information flows in traditional systems and contemporary systems that are impacted by new innovations in IT, and then offers recommendations to achieve an optimal information system.
\end{abstract}

Keywords: Accounting Information Systems, Enhanced Business Reporting, Information Value, Real Time Economy.

\section{INTRODUCTION}

The impact of Information Technology (IT) is felt in all spheres of human activity, but the resulting benefits vary. It has indeed been a boon to the marketing community. But some fields have not reaped the benefits to the fullest extent. The field of financial information reporting is one such. In a typical supply chain, the financial flow includes thousands of invoices and payments in a given year. The scale of this problem is challenging businesses to find ways to streamline their processing. There are also considerable savings to be obtained by improvements in processing of financial transactions. With the advent of innovations in IT and the increased use of Enterprise Resource Planning (ERP) systems, the situation has vastly improved in many areas. In order for executives to accurately evaluate the profitability of their operations, they must receive useful revenue and cost information on a timely basis. Major changes in processing cost information have occurred in the 1980s and 1990s [4, 18, 19]. Manufacturers converted to the Just-In-Time (JIT) approach to manufacturing and the accountants changed their approach to gathering cost information. As a result, cost management from a total supply chain perspective is being utilized increasingly by executives.

All organizations in the supply chain have both Accounts Payable (A/P) and Accounts Receivable (A/R) activities. Each invoice is an A/P from the downstream buyer's perspective and an A/R from the upstream seller's point of view. Multiple invoices, however, are often paid by a single payment. This requires information as to which specific invoices are covered by a remittance. Financial flows also include information transfer via Electronic Invoice Presentment (EIP) and electronic payments [1, 11, 12]. Until recently, information and financial flows were treated separately exacerbating the potential for inefficiency.

For the overall profitability of an enterprise, it is necessary that the scope of cost-reduction initiatives include both upstream (supplier) and downstream (customer) members of their supply chains [8]. According to Barry [2], by optimizing the financial supply chain, supply managers and their enterprises can reduce their working capital needs by as much as 20-25 percent. This is achieved by using better invoicing control and cash-flow management. Before the introduction of e-commerce, in order to run an efficient physical supply chain, it was necessary to encounter 


\section{Issues in Information Systems}

Volume XII, No. 1, pp. 36-43, 2011

excess working inventory and excess working capital to cope with the uncertainty of demand. The strategy consisted of having excess inventory, capacity and labor to compensate for demand forecasting limitations, inefficient distribution and lack of supply chain visibility [2,3]. The increased use of the Internet and Extensible Markup Language (XML) can be expected as a result of increased automation in supply chain transactions. To minimize disruptions during the change over to automation, it is necessary that companies must incorporate e-business concepts into their overall business strategies. The rest of this paper is organized as follows. A contemporary view of how information flows in modern enterprises is given in the next section. This is followed by a discussion on the legacy of manual processes. The subsequent sections describe the efforts to automate the critical processes that occur in financial transactions. A summary is presented in the last section.

\section{THE “NOW” ECONOMY}

The current business practices demand a much faster decision making process as many enterprises must manage their cash on a day to day basis to be able to apply it and borrow it overnight, and manage receivables and payables on a day to day basis [21]. The real time enterprise can be compared to a giant spreadsheet in which new information, such as an order, is automatically processed and percolates through a firm's computer systems and those of its suppliers. In a typical manufacturing enterprise, the value chain model consists of the following sequence of activities: inbound logistics, operations, outbound logistics, marketing \& sales, and service. The objective is to offer the customer a level of value that exceeds the cost of activities [16, 17]. In addition to the above primary value chain activities, we also need to consider the following supporting activities: firm infrastructure, human resource management, technology development, and procurement. Supply chain management (SCM) can be defined as the combination of art and science of improving the way an enterprise finds the raw components it needs to make a product and delivers it to customers. Viewed from this perspective, SCM is an important part of the overall value chain model. This approach is useful in analyzing the impact of Information and Communications Technologies (ICT) on the manufacturing environment.

The Financial Supply Chain is increasingly recognized as an area offering significant potential for generating bottom-line improvements and creating competitive advantage. According to Killen Associates, a typical billiondollar company spends approximately \$27 million annually for unnecessary working capital and inefficient processing functions because they lack visibility into the Financial Supply Chain and receivables [3, 10]. It has also been estimated that the total value locked up in inefficiencies associated with the global supply chain are between \$500 billion and one trillion US\$.

The Financial Supply Chain refers to the end-to-end trade processes and information that drive a company's cash, accounts, and working capital. From a buyer's perspective, this involves the full procurement-to-payment process. For the seller, it is the order-to-cash cycle.

In both cases, the goal of the Financial Supply Chain is to optimize:

- Accounts payable and receivable

- Cash management

- Working capital

- Transaction costs

- Risk

- Administration

But unlike the Physical Supply Chain, which has seen improvements ranging from containerization to fulfillment management, there remain significant performance gaps in the Financial Supply Chain that contribute significantly to the trapped value identified above. These gaps are the result of the:

- Time required to create, transfer and process paper documentation 


\section{Issues in Information Systems}

Volume XII, No. 1, pp. 36-43, 2011

- Cost and errors associated with manual creation and reconciliation of documentation

- Lack of transparency in inventory and cash positions when goods are in the supply chain

- Disputes arising from inaccurate or missing data

- Fragmented point solutions that do not address the complete end-to-end processes of the trade cycle

Financial Supply Chain benefits have proved elusive because of the complexity associated with international trade. The end-to-end trade cycle involves a number of different types of parties needing to exchange information and a variety of contractual documents in a timely manner. Point solutions have provided limited value with limited ability to scale and broader e-Commerce initiatives have failed to provide the platform to manage the complexity of Global Trade, typically being proprietary by nature and/or simply consolidating data and being unable to replace the full content and legal context of paper documents.

To overcome these barriers, enabling technology must meet critical pre-requisites to be practical, and deliver enduring value to each member of the trading community:

- Progressive acceleration, automation and optimization of the Financial Supply Chain processes leading to paperless trade

- Scaleable to support all settlement types, all documents, all parties and cross industry applicability

- Interoperability with e-Commerce and Trade Community platforms and applications

- Incremental application components to deliver targeted value, speed of implementation and a direct return on investment

- $\quad$ Trusted Third Party platform with neutrality through governance

- Full coverage of the commercial, logistics, financial and regulatory documents required for international trade.

Even though outsourcing may reduce the cost of the actual product, some times they decrease the capital efficiency of the value chain for the following reason. Plants and equipment are often far more expensive to finance in emerging market countries [8]. Furthermore, inventory tends to get pushed downstream to suppliers, which often have a higher cost of capital. In addition, global operations can add weeks to the value chain, tying up as much as 30 percent of product price in working capital.

Enterprise Resource Planning (ERP) systems were expected to integrate operational transactions and informational requirements of managers for strategic decision-making [4]. However, in some cases, the rigidity of the "template approach" has resulted in unsatisfactory results. Innovations in information technology provide a seamless flow of information at a relatively low cost. Companies can leverage the core competencies of their partners to create value, without trying to own the entire supply chain. The vertically organized enterprise is being replaced by hubs of value, described as a 'business ecosystem' by Harteley-Urqhart [10]. The traditional model is asset intensive and the emphasis is on value chain control. Information flow in such enterprises is managed through ownership. The new approach can be described as an extended value chain. The focus is on divestment of assets. Access to information is obtained by collaborating with partners. The extended value chain focuses on external optimization, synchronization and information. Financial supply chain can be optimized by integrating information about the physical flow of goods with the financial flow. The objective is to find the right strategy and combination of trade-offs in terms of costs and assets.

\section{INFORMATION FLOWS}

The typical information flows that occur in an enterprise are shown in Appendix I. Effective information systems perform several key functions throughout the three stages of input, processing, and output. These functions include data collection, data maintenance, data management, data control, and information generation [25]. Before the days of the super computers and software packages, the manual processing of data created many problems because people, no matter how efficient, make mistakes. In addition, the processing of data in paper form takes time. The 
mailing of invoices or payments slows the process. The preparation of the Voucher Package for accounts payable takes time [5, 7]. The tracking of inventories manually is an almost super human endeavor for large complex enterprises when done manually. The information to properly manage inventories is not there in a timely manner.

But even in the manual process era, it was still possible to control the financial flow efficiently. For management to get a handle on its financial resources, they must start with the budget process. This means starting with a realistic sales forecast that reflects the sales fluctuations that occur during the year. With a good sales forecast that can be converted into purchase/production requirements, inventories can be planned and controlled. Without a sound plan, management is always putting out fires and efficient management of the financial supply will not be possible. With a sound plan, inventories can be kept to a minimum, the requirement for borrowing can be reduced, and as a result, financing costs can be lowered. Furthermore, the best time to arrange a company's financing is immediately after the budgeting process takes place. It must also be noted that the budget sales forecast is not cast in stone as the year goes along, it must be reviewed and adjusted if the actual sales pattern changes. For example, at Toyota, there is a monthly review and production levels are adjusted according to the changes seen in the deviation from budget by actual sales [15].

In the manual processing days, control of cash payments was done through the use of the Voucher Package. This system required four documents to be matched before a payment could be authorized and an Accounts Payable could be recorded on the books. The four documents in this package are: Purchase Requisition, Purchase Order, Receiving Report, and Vendor Invoice. The Purchase had to be signed by a person with the authority to initiate a Purchase Requisition. The Purchase Requisition was sent to the purchasing department where a Purchase Order was generated. When the goods were received, A Receiving Report was prepared after an examination and count of the goods. These three documents were matched to the Vendor Invoice and if all four documents agreed, a payment was scheduled. If a discount was involved, the discount was evaluated to see if it was cheaper to borrow money from the bank or the vendor. The process was cumbersome, and time consuming.

The control of accounts receivable in the manual days consisted of individual subsidiary ledgers being kept for each customer. As sales were made on credit and payments received, these transactions were posted by hand. Posting to the wrong account and addition errors occurred. The collection of the receivables was delayed by creative delivery of payments to the post office in some cases. Since the post office is considered to be the agent of the firm when a bill is mailed to a customer, the customer could simply wait for the due date or the discount date and mail the payment. If the mail was slow, this could add several days to the collection process. Payment was made on the due date by law, but the firm did not receive the funds until the mail was delivered. In some cases, companies delivered payments to remote post offices so that it would take extra time to get to the firm doing the billing. As a result, financing costs were increased.

The control of bad debt expense starts with knowing your customers and the establishment of credit criteria that are enforced. It is too late to realize that you have a potential poor customer on your hands when you do an aging of accounts receivable and determine that you have an overdue account. A nonpaying customer means you failed somewhere in the review process and that you literally gave your goods away for nothing.

One of the main stumbling blocks in way of automation of financial transaction processing is the mapping of Empirical Relational System (ERS) into Numerical Relational System (NRS). The Empirical Relational System encompasses the relationships in real life while the second their measurement [22]. The real time business represents a much changed ERS when compared to traditional firms with a reduced business cycle. Ultimately, the success of the system depends upon the accuracy of this mapping.

\section{STRATEGIC ROLE OF INFORMATION TECHNOLOGY}

The strategic role played by information technology can be analyzed by using McFarlan's Strategic Grid as shown in Appendix II. The strategic grid is a two-dimensional graph. The horizontal or X axis measures how IT affects the organization's strategy. For some companies, such as Microsoft, Wal-Mart and FedEx, market positioning is 


\section{Issues in Information Systems}

Volume XII, No. 1, pp. 36-43, 2011

contingent on IT initiatives. The vertical or Y axis gauges the impact of IT on operations. For other organizations, such as eBay, Amazon and AOL, survival pivots on robust IT operations. A brief interruption in IT-enabled service may be costly, if not crippling.

The grid created by the $\mathrm{X}$ and $\mathrm{Y}$ axes can be subdivided into four quadrants: "support" or low strategic and operational impact; "turnaround" or high strategic impact and low operational impact; "factory" or low strategic impact and high operational impact; and, "strategic" or high strategic and operational impact. While IT projects in turnaround cover new technologies that would exploit market opportunities, projects in support encompass process enhancements for unique users. If an enterprise is looking towards automating most of its transaction processing, then it is moving towards the Strategic quadrant.

With the advent of the computer and the UPC labeling much has been done to improve the supply of information necessary to improve the management of the financial supply chain. However, no matter how good the data flow is to provide management with information, it still starts with a sound plan. With a sound plan and good current information, management can do a much more efficient job of controlling inventory levels and preserving cash. With the innovation, the need for control over cash payments is still necessary. The Voucher Package is still necessary. In the modern age, the documentation contained in the package is somewhat different. No longer are there Purchase Requisitions and individual Purchase Orders. If the company is operating with a Just-In-Time system, there are no Receiving Reports. The Vendor Invoice is electronically sent. In the current system, the purchasing department evaluates vendors to determine if they can provide the necessary items in the quantity and quality desired. If the vendor passes, a long term purchase contract is arranged. The vendor is given a copy of the production schedule that details what is needed and when it is needed. The vendor is then required to deliver what is needed, when it is needed. When a Vendor Invoice is transmitted electronically to the customer, it is evaluated to determine if it is coming from an authorized vendor, for contracted items, in the quantity called for by the production schedule [13, 21]. If everything agrees, payment is authorized and scheduled for payment on the due date. On the proper due date, payment is transmitted electronically. This results in a great deal of time being saved in the preparation of the Voucher Package and associated documentation.

While accounts receivable is now electronically processed, the key to reducing float has come about through the electronic processing of payments. No longer is there a lengthy wait for a company to receive its money because the customer dropped the payment in the mail. With electronic payment the firm receives its money promptly and has it in the bank that day. Thus, the money is available in a much more expeditious time.

Bloated inventories because we ordered the wrong items, or we produced the wrong products, or we overproduced should be a thing of the past. With a sound plan and the information now provided by the computerized systems, management can eliminate overstocking and obsolete inventories. This still requires a constant monitoring of actual sales and a reconciliation of current inventory levels and production plans to determine if the change in the actual sales pattern has changed significantly from the sales budget and as a result requires a change in production plans.

Innovations in Radiofrequency Identification (RFID) have a gone a long way in answering the information processing challenges that can occur in financial supply chains. Nowadays, large enterprises like Wal-Mart require their vendors to place RFID tags on incoming pallets. The adoption of RFID is a strategic decision. For unfettered, un-mandated, adoption to take place an organization must be able to justify the cost of the investments in the technology in terms of when and how they could expect to reap the benefits of that investment. In most cases, these benefits have a direct impact on the bottom line. It is therefore a primary driver for such voluntary and no-stringsattached adoption [6, 9].

Organization information systems have evolved significantly in the last fifty years, and they will continue to evolve. They have changed from paper and pencil to computer driven systems. While the means have changed significantly, the providers have also changed and in our estimation will continue to change. At one time the management accountant was the principal provider of information for strategic decision-making. Today, the managerial 


\section{Issues in Information Systems}

Volume XII, No. 1, pp. 36-43, 2011

accountant has withdrawn from this function, and is now a recipient of information provided by the organization information system. The MIS system is now the provider of basic information such as inventories, personnel costs, equipment costs, etc. In short the ERP system collects data and distributes it to the relevant users.

It is assumed that the financial accounting system is independent of an organization's MIS system. While this may be true in part, it relies heavily on this system to prepare its reports. These reports in many respects are oriented to outsiders who will use these reports to assess the financial condition of the firm. While important, they are not in a framework for making executive decisions. This shortcoming can be overcome by the MIS system creating the necessary reports.

The approach to ensure that there are no information gaps in the financial transaction processing, requires that the change has to be incremental in nature. The first stage consists of identifying all the essential documents that need to be digitized. In the second stage selective automation of processing those documents that are critical in nature. Full coverage of all the commercial, logistics, financial, and regulatory documents is done at the final stage.

\section{CONCLUSION}

With reference to the Strategic Grid proposed by McFarlan (Appendix II), all enterprises have to move from Support quadrant to Strategic quadrant in order to keep up with the competition. Contemporary information systems provide the real time data used by accountants to prepare financial documents. Jim Shepherd of AMR Research states that the notion that a company can transform itself into an e-business by simply using a piece of software and adding it to its existing infrastructure is wrong and dangerous [18]. As supply chain management becomes more integrated with financial supply chain, it is critical that we have reliable information sources. In order to fully realize the positive impact of IT, it is necessary to integrate physical, informational and financial supply chains. In this paper, we have analyzed various transactions that take place in a typical financial transaction processing scenario at the enterprise level. Future research involves developing a framework that enables extraction of relevant information that is needed for optimal results. We also plan to study the ways in which the new innovations in information technology can be harnessed in the context of inventory management and its effect on the overall financial supply chain efficiency.

\section{REFERENCES}

1. Atkinson, A. A., et al. (2001). Management Accounting. Upper Saddle River, NJ: Prentice Hall.

2. Barry, J. (2003). Lessons Learned from Physical Supply Chain. Inside Supply Management, 14, (5), 21.

3. Carbo, B. (2002). Align the Organization for Improved Supply Chain Performance, ASCET, Vol. 4, May 15.

4. Carton, F. et al. (2005). Understanding the Impact of Enterprise Systems on Management Decision Making: An Agenda for Future Research. The Electronic Journal of Information Systems Evaluation, 8 (2), 99-106.

5. Cooper, R. et al (1988). How Cost Accounting Distorts Product Costs. Management Accounting, 22 - 26.

6. Fontelera, J. (2007). Quest for the RFID Supply-Chain Holy Grail: ROI. Converting Magazine, 25(9), 35-35.

7. Garrison, R. H., et al (2003). Managerial Accounting. New York, NY: McGraw Hill / Irwin.

8. Handfield, R. and Nichols, E. (2002). Supply Chain Redesign. Upper Saddle River, NJ: Prentice Hall.

9. Hardgrave, B. C., Langford, S., Waller, M., \& Miller, R. (2008). Measuring the Impact of RFID on Out of Stocks at Wal-Mart. MIS Quarterly Executive, 7(4).

10. Hartley-Urquhart, Roland (2006). "Managing the Financial Supply Chain," Supply Chain Management Review.

11. Hirschey, M. (2000). Managerial Economics. New York, NY: The Dryden Press.

12. Hongren, C. T et al. (2000). Cost Accounting: A Managerial Emphasis. Upper Saddle River, NJ: Prentice Hall.

13. Johnson, H. Thomas. (1992). It's Time to Stop Overselling Activity Based Costing. Management Accounting, September, 26-35.

14. Kaplan, R. S., Weiss, D., et al. (1997). Transfer pricing With ABC. Management Accounting, May, 20-28.

15. Lee, John Y. (1987). Managerial Accounting Changes for the 1990s. Artesia, CA: McKay Business Systems. 
16. McFarlan, W. E. (1984). Information Technology Changes the Way You Compete. Harvard Business Review, 62(3), 98-103, May/June.

17. Nancy W. (2000). Fundamental Management Accounting Concepts. Boston, MA: McGraw Hill.

18. Neuman, B. R. and Jaouen, P. R. (1986). Kanban, ZIPS, and Cost Accounting: A Case Study. In Focus on Industry, Journal of Accountancy, August, 132-141.

19. Ogden, Jeffrey, A. et al. (2005). Supply Management Strategies for the Future: A Delphi Study. The Journal of Supply Chain Management, 41 (3), 29-48.

20. Porter, Michael (1985). Competitive Advantage: Creating and Sustaining Superior Advantage, New York: Free Press.

21. Sori, Z. M. (2009). Accounting Information Systems (AIS) and Knowledge Management: A Case Study. American Journal of Scientific Research, Issue 4, 36 - 44.

22. Vasarhelyi, M. A. and Alles, M. G. (2008). The "Now" and the Traditional Accounting Reporting Model: Opportunities and Challenges for AIS Research. International Journal of Accounting Information Systems, Issue 9, $227-239$.

23. Weber, K. B., and Denna, E. L. (1997). A New Accounting System Is Emerging. Management Accounting, July, $22-30$.

24. Weygandt, J. J. et al. (2002). Management Accounting. New York, NY: John Wiley. 140-143.

25. Wilkinson, J. W. (1993). Accounting Information Systems. New York, NY: John Wiley. 
APPENDIX I

Financial Information Flows in a Typical Enterprise (Adapted from [21])

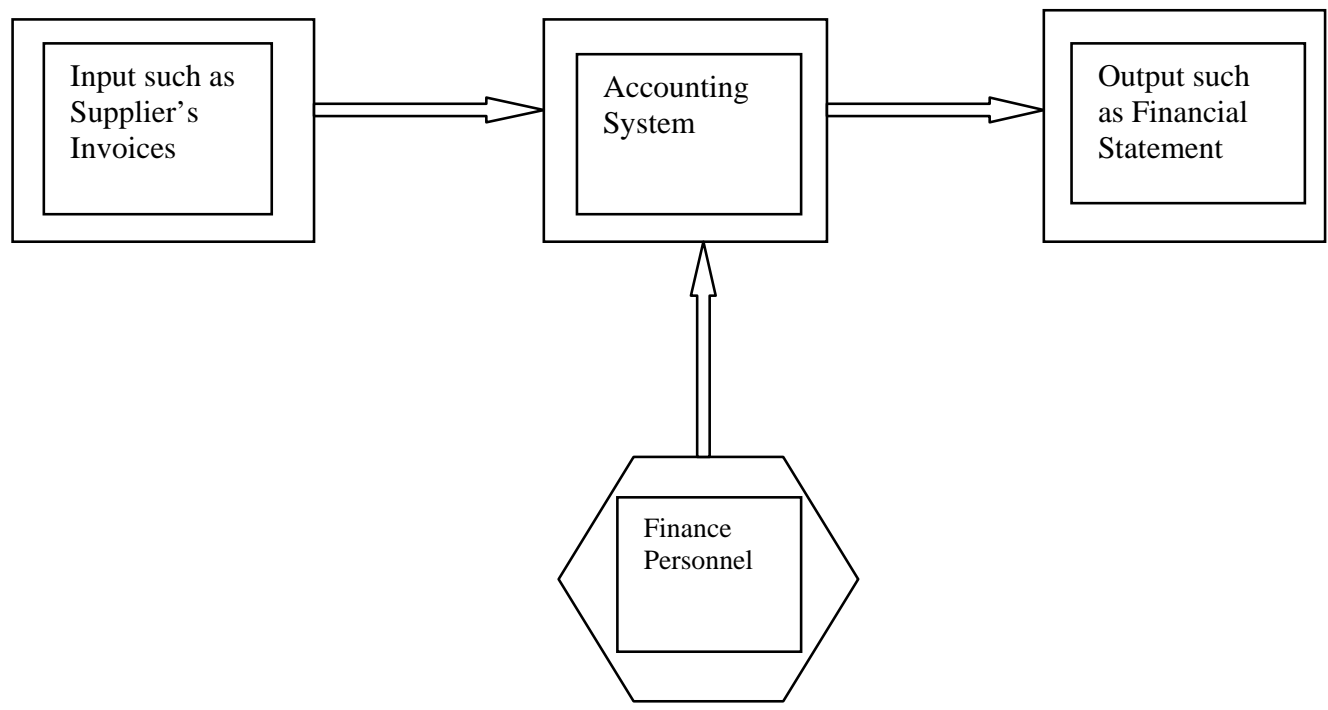

APPENDIX II

McFarlan's Strategic Grid for a Typical Enterprise (Adapted from [16])

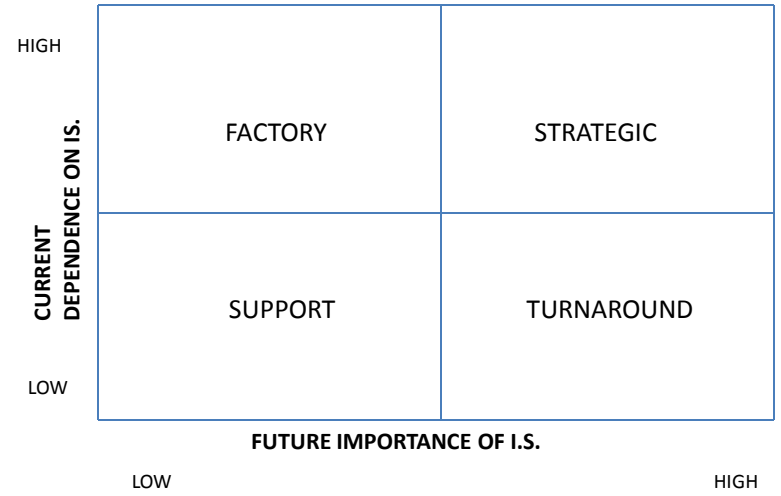

